\title{
Proceeding
}

Supplementary Issue: Summer Conferences of Sports Science. First International Conference in Iraq on Sport for Peace, 4 April 2019. Baghdad Science Institute, Baghdad, Iraq.

\section{A new incremental and comprehensive approach to preschool dance education}

\author{
ILZE M. LIEPA 14 , ALINA B. GRUDSKAYA² \\ ${ }^{1}$ Charity Foundation for Contributing to the Development of Choreography and Art, Moscow, Russia \\ ${ }^{2}$ Russian National Ballet School of Ilze Liepa in Saint-Petersburg, Saint-Petersburg, Russia
}

\begin{abstract}
The article describes the new technique of teaching the basics of choreography to 3 to 6 years old children using the methodology of Russian classical ballet school, modern ballet rhythmoplasty and authors' many years teaching experience. The article provides a detailed analysis of children teaching program «Little ballerinas» by phases. The most important for children of this age is to let them plunge into the atmosphere of choreographic art, classical music, discipline and independent creativity. One of the main factors of success is the teacher and his/her willingness to interest and involve children in the process of work and creation. Keywords: Choreography; Classical ballet school; Rhythmoplasty; Classical dance; Development dynamics.
\end{abstract}

\section{Cite this article as:}

Liepa, I.M., \& Grudskaya, A.B. (2019). A new incremental and comprehensive approach to preschool dance education. Journal of Human Sport and Exercise, 14(5proc), S2052-S2075. doi:https://doi.org/10.14198/jhse.2019.14.Proc5.27

\footnotetext{
Corresponding author. Charity foundation for contributing to the development of choreography and art, People's Artist of Russia, People's Artist of Karelia. Moscow, Russia.

E-mail: Kozina.n.vladimrov3@gmail.com

Supplementary Issue: Summer Conferences of Sports Science. First International Conference in Iraq on Sport for Peace, 4 April 2019. Baghdad Science Institute, Baghdad, Iraq.

JOURNAL OF HUMAN SPORT \& EXERCISE ISSN 1988-5202

(c) Faculty of Education. University of Alicante

doi:10.14198/jhse.2019.14.Proc5.27
} 


\section{INTRODUCTION}

Today's children start mastering the basics of choreography, painting, musical art and foreign languages very early. The teaching experience and well proven child friendly dance techniques show that even 3 years old children can focus their attention, hear and appreciate classical music, learn effectively and take part in choreographic performance. Making children involved in choreographic art and creativity is a very important component of their education (Gestwicki, 2013; Hendrick, J., \& Weissman, 1996; Powell et al., 2006). The role of great Russian and foreign composers' musical works in the formation of child's musical taste is very important, since it influences all his/her later life. Musicality, aesthetics, physical development and, of course, moral education - all these lay down the foundations of teaching choreography to children. Thus, classical dance is an essential element in the harmonious physical and spiritual well-being of the child (Groark 2005; Rolfe, 2004; McLachlan et al., 2013).

\section{METHODS}

Discipline, concentration, development of memory and musical perception, memorization of movements, as well as confidential contact and interaction with the child are of special importance for teachers during the initial training year. From the first lessons, the atmosphere in the ballroom should be working and creative. To hold the attention and interest of children, the dynamics should be varied with transitions and combinations of physical and game exercises. The plan and content of the lesson depend on the psychophysical state of children, the emotional stability of information and physical load perception (Vanderloo, 2014; Pfeiffer et al., 2013). Developing an individual approach to a specific group of children, the teacher involves play-based activities with various objects and techniques. Any exercise must begin with an analysis of its elements. A special attention is paid to what the children should do and how. The complication or simplification of the presentation depends on the psychological perception of children, their age specific characteristics. Every child has its own personality, and it is important to note that there are several learning styles, namely:

- Visual (visual images) - it's enough only to show the exercise;

- auditory (comprehension of auditory images) - the teacher explains the task and the child performs it;

- kinaesthetic (learning through physical sensations) - the exercise must be shown in a bodily way;

- digital (abstract-logical images) - the teacher must compare body movement or position with an image.

According to the observations of professional psychologists and authors' pedagogical experience, children better perceive information through visual images and physical sensations.

In a new group of trainees, it is difficult to immediately understand what the better way of representing information is. Therefore, the task of the teacher is to explain each movement, to show it, to find the right words for figurative perception, and to correct each child.

\section{PROGRAM "LITTLE BALLERINAS» FOR TEACHING THE BASICS OF CHOREOGRAPHY TO CHILDREN}

The program has been designed to ensure a step-by-step preparation of children for choreography classes and provides a three-year period of education for children aged 3 to 6 years. The training methodology is aimed at revealing the creative potential of the child, strengthening and developing the muscular corset through independent work and team interaction, as well as mastering the basic exercises of classical ballet. 


\section{Goals}

- Development of physical coordination;

- Development of trainee's potential and self-expression;

- General physical training, strengthening of muscle corset system,

- Preparations for exercises of classical ballet.

\section{Trainee's objectives}

- To understand and fulfil teacher's demands;

- To work and interact in a team;

- To adapt to independent work (without mother's presence);

- To get acquainted with his own body (attention to body parts: knees, feet, elbows, head, hands, fingers and toes);

- To learn the basics of classical ballet.

A basic lesson of 60 to 90 minutes is developed for each year of study, based on the Basic module of the first half year of the studies. All the exercises and their sequence are methodologically sound, which ensures the achievement of the final result of each intermediate training stage and the acquisition of certain choreographic skills corresponding to trainees' age. During the first year, young children get acquainted with the parts of their bodies, learn to coordinate movements, and master the basic elements. The basic module consists of several sets of exercises with conditional names: «Warm up», «Parterre gymnastics», «Milieu» and «Choreographic miniatures».

«Warm up» is a separate set of exercises, since at such an early age there is a need for an introductory playbased part to psych the children up for full-time lessons with simultaneous physical warming up of all the main muscles and joints. "Parterre gymnastics» allows achieving the following results: to develop and strengthen the muscles and ligaments; to develop a ballet posture; to improve coordination of movements; to master the basic principles of classical exercises. Exercises of the «Milieu» are aimed at developing techniques for performing choreographic elements, exploring the hall space, developing the image thinking and musical ear. This set of exercises is also important for changing the movement pattern after the «parterre». Exercises of the «Choreographic Miniatures» set, in turn, allow developing musicality and dance improvisation skills.

During the next periods of training up to the age of 5, the Basic module of exercises becomes complicated by new elements, and exercises for stretching of inguinal and popliteus muscles and ligaments are added. The third year of training for 5 - 6 -year-old is characterized by more complicated choreographic elements and the study of classical barre and milieu exercises.

\section{BASIC COURSE}

First year of training. First half year, 3-3, 5-year-old. Basic module. (Lesson duration is 60 minutes)

1 «WARM UP»

1.1 «Bow» $2 / 4$ time.

1.2 «Walking around»

1.4 «Wrists warm up» 
The exercise is aimed at developing coordination and fine motor skills.

1) «Wrists turns»

2) «Fingers meet»

3) «Little beaks»

4) «Droplets»

5) «Wings of a swan» $4 / 4$ time.

\section{PARTERRE GYMNASTICS}

Parterre gymnastics consists of exercises aimed at preparing muscles and ligaments for the barre and milieu exercise. Exercises are performed while sitting, lying on the floor and kneeling. Before starting, the children should get acquainted with the body parts involved and their interaction. Before starting to study movements in the supine position, the teacher explains that the lower back should be pressed to the ground, using the most understandable figurative expressions for the children of this age.

\section{Feet work}

This set of exercises is aimed at stretching and strengthening the ankle and popliteal ligaments, as well as the development of lower turnout. 2/4 time.

\section{Folds}

The exercise is aimed at stretching the popliteal ligaments, stretching and strengthening the back muscles. 2/4 time.

\section{Butterfly}

The exercise is aimed at stretching the inguinal ligaments and the turnout development.

2/4 time.

\section{Fishing rod}

The exercise is aimed at hip joints stretching, stretching and strengthening of the back.

$3 / 4$ time.

\section{Sunbeam}

During the exercise the popliteal ligament and the hamstring are worked out.

2/4 time.

\section{Bicycle}

The exercise is aimed at strengthening the abdominal muscles. 2/4 time.

\section{Mouse in the hole}

The exercise is aimed at developing flexibility in thoracic and lumbar sections of the back, as well as at the coordination of movements. 3/4 time.

\section{Little fish}

The exercise is aimed at developing flexibility in thoracic and lumbar sections of the back 2/4 time.

\section{Basket}

The exercise is aimed at stretching and strengthening back and hips muscles. Shoulder joints are also active. $6 / 8$ time.

Exercises Little fox and Cat are performed in succession to one piece of music:

\section{Little fox}

The exercise is aimed at strengthening the muscles of back, abdomen, hips and the ligaments in knee joints. 2/4 time.

Cat («Friendly and grumpy cat»)

Exercise to develop flexibility of the back, strengthening the abdominal muscles. 2/4 time. 


\section{Train}

The exercise is aimed at working the hip joints, back and abdomen muscles, coordination of movements. 2/4 time.

\section{Suffering}

The exercise is aimed at stretching the popliteal ligaments, heel strings (Achilles) and back muscles.

$4 / 4$ time.

\section{Stairs}

The exercise is aimed at stretching the popliteal ligaments, heel strings (Achilles), inguinal ligaments, hip joints work. 2/4 time.

\section{Teddy Bear}

The exercise is aimed at stretching and relaxation of the back muscles at the spinal column. 2/4 time.

\section{Exercises with accessories}

These exercises are aimed at platy podia prevention, massage and the development of coordination when working with an accessory. They are performed with massage mat, inflatable needle balls ( $7 \mathrm{~cm}$ of diameter) and hemispheres.

\section{Exercises with a ball for hands}

This set of exercises is performed without stopping. 4/4 time.

\section{Exercises with a ball for legs}

The set of exercises is performed without stopping. 2/4 time.

\section{Magic lock}

The exercise is aimed at developing coordination, strengthening the abdominal muscles, popliteal ligaments and feet work. $4 / 4$ time.

\section{Massage mat}

The exercise is aimed at preventing platy podia and strengthening the foot arch. Steps on the massage mat and hemispheres with musical accompaniment (barefoot). 3/4 time.

\section{MILIEU \\ Musicians}

A set of coordination exercises, developing imaginative thinking, musicality and concentration. Play-based activities.

1) «Piano»

2) «Flute»

3) «Drums»

2/4 and 3/4 time.

\section{Jump}

Jumps from sixth position. 2/4 time.

\section{Acting talent}

The exercises are aimed at the development of dance imagination, coordination and musicality. Interaction between trainee and teacher, trainee and partner.

1) «Rain»

2) «Snowflake»

3) «Snowballing» 2/4 time.

\section{Clown}

The exercise is aimed at the development of dance imagination, coordination and musicality. 2/4 or 4/4 time. Diagonal steps

Exercises are performed on a diagonal (one after another).

1) Marching (legs lift with bent knees) 
2) Hops

3) «Swans» (walking high on tiptoes).

2/4 и 3/4 time.

\section{Musical interlude}

The exercises are aimed at developing musical ear and coordination.

1) Clapping hands

2) «Gymnastics»

2/4 time.

Jumping rope

Exercises are aimed at coordination and developing turnout. Exercises are performed on a jumping rope stretched on the floor.

1) «Rope-walker»

2) «Sidestep»

3) «Jumping rope» $2 / 4$ time.

\section{CHOREOGRAPHIC MINIATURES}

The exercises of this set are aimed at the development of dance imagination, improvisation, musicality and rhythmic hearing.

Rain

The set of exercises is performed to one piece of music.

1) «Raining» hands.

2) «Raining» feet. 3/4 time.

\section{Musical train}

The exercise is aimed at the orientation in the hall, interaction, development of coordination, memory, imaginative thinking and improvisation. 2/4 or 4/4.

\section{Snake}

The exercise is aimed at the orientation in the hall, interaction between trainees. $2 / 4$ or 4/4.

\section{Bow}

2/4 time.

\section{First year of training. Second semester, 3,5-4-year-old. (Lesson duration is 60 minutes)}

\section{WARM UP}

This set of exercises is more complicated.

\section{"Bow»}

2/4 time.

\section{Walking around}

New elements are added to the set of Basic module exercises:

1) walking pointing feet;

2) walking on tip toes;

3) walking on the heels;

4) walking on tip toes in deep squat from sixth position («geese»), straight back, hands on knees;

5) running on tiptoes;

6) steps with pointed feet, hands in the starting position (march);

2/4 time. 


\section{Shoulders warm up}

4/4 time.

\section{Wrists warm up}

The exercise is aimed at developing coordination and fine motor skills.

1) «Wrists turnouts»

2) «Fingers meet»

3) «Little beaks»

4) «Droplets»

5) «Wings of a swan» 4/4 time.

\section{PARTERRE GYMNASTICS}

The basis of the parterre gymnastics for this training period are Basic module exercises, new exercises are also added.

\section{Feet work}

The set of exercises is aimed at stretching and strengthening the ankle and popliteal ligaments, as well as the development of lower turnout. 2/4 time.

\section{Folds}

The exercise is aimed at stretching the popliteal ligaments, stretching and strengthening the back muscles 2/4 time.

\section{Butterfly}

The exercise is aimed at stretching the inguinal ligaments and the turnout development. 2/4 time.

\section{Fishing rod}

The exercise is aimed at hip joints stretching, stretching and strengthening of the back. 3/4 time.

\section{Sunbeam}

The exercise is aimed at working the popliteal ligament and the hamstring. 2/4 time.

\section{Bicycle}

The exercise is more complicated, it is still aimed at strengthening the abdominal muscles. 2/4 time.

\section{Mouse in the hole}

The exercise is aimed at developing flexibility in thoracic and lumbar sections of the back, as well as at coordination of movements. 3/4 time.

\section{Little fish}

The exercise is aimed at developing flexibility in thoracic and lumbar sections of the back 2/4 time.

\section{Basket}

The exercise is aimed at stretching and strengthening back and hip muscles. Shoulder joints are also active. $6 / 8$ time.

Next, new exercises in the position lying on the floor (on the rug) are added:

\section{Plane}

This exercise is aimed at strengthening the back muscles. It is performed simultaneously by two children with different tasks. 2/4 time.

\section{Roly-poly toy}

The exercise is aimed at strengthening abdominal and neck muscles. Time 2/4.

\section{Frog}

The exercise is aimed at developing the hip joints turnout and stretching of the inguinal ligaments. 2/4 time. Then the exercises continue in the order of the Basic module, but with a new numbering. Exercises 2.13, 2.14 and 2.15 are performed in succession to a single piece of music: 


\section{Fox}

The exercise is aimed at strengthening the muscles of back, abdomen, hips and the ligaments in knee joints. 2/4 time.

Cat («Friendly and grumpy cat»)

Exercise to develop flexibility of the back, strengthening the abdominal muscles. 2/4 time.

A new exercise is added:

Hummock («Evil cat»)

The exercise is aimed at stretching the heel strings (Achilles) and hamstrings, as well as at working the back muscles of the thoracic spine.

2/4 time

The Basic module exercises.

\section{Train}

The exercise is aimed at working the hip joints, back and abdomen muscles, coordination of movements. 2/4 time.

\section{Suffering}

The exercise is aimed at stretching the popliteal ligaments, heel strings (Achilles) and back muscles. 4/4 time.

\section{Stairs}

The exercise is aimed at stretching the popliteal ligaments, heel strings (Achilles), inguinal ligaments, hip joints work.

\section{2/4 time.}

\section{Teddy Bear}

The exercise is aimed at stretching and relaxation of the back muscles at the spinal column. 2/4 time.

\section{Exercises with accessories}

These exercises are aimed at platy podia prevention, massage and the development of coordination when working with an accessory. They are performed with massage mat, inflatable needle balls ( $7 \mathrm{~cm}$ of diameter) and hemispheres.

\section{Exercises with a ball for hands}

A set of exercises is performed without stopping. 4/4 time.

\section{Exercises with a ball for legs}

A set of exercises is performed without stopping. 2/4 time.

\section{Magic lock}

The exercise is aimed at developing coordination, strengthening the abdominal muscles, popliteal ligaments and feet work. $4 / 4$ time.

\section{Massage mat}

The exercise is aimed at preventing platy podia and strengthening the foot arch.

Steps on the massage mat and hemispheres (barefoot) with musical accompaniment.

$3 / 4$ time.

\section{MILIEU}

\section{Musicians}

A set of coordination exercises, developing imaginative thinking, musicality and concentration. Play-based activities.

1) «Piano»

2) «Flute»

3) «Drums» 
2/4 and 3/4 time.

\section{Jump}

2/4 time.

\section{Acting talent}

The exercises are aimed at the development of dance imagination, coordination and musicality. Interaction between trainee and teacher, trainee and partner.
1) «Rain»
2) «Snowflake»
3) «Snowballing»
2/4 time.

Diagonal

Exercises are performed on a diagonal (one after another).

1) Marching (legs lift knees up)

2) Hop

3) «Horses»

3) «Swans» (walking high on tiptoes).

2/4 и 3/4 time.

\section{Musical interlude}

The exercises are aimed at developing musical ear and coordination.

1) Clapping hands

2) «Gymnastics»

3) Galloping around 2/4 time.

\section{Jumping rope}

Exercises are aimed at coordination and developing turnout. Exercises are performed on a jumping rope stretched on the floor.

1) «Rope-walker»

2) «Sidestep»

3) «Jumping rope» $2 / 4$ time.

\section{CHOREOGRAPHIC MINIATURES}

The exercises of this set are aimed at the development of dance imagination, improvisation, musicality and rhythmic hearing.

\section{Rain}

1) «Raining» hands

2) «Raining» feet. 3/4 time.

A new dancing exercise is added to the Basic module

\section{Dance with a doll}

2/4 time.

Snake

$2 / 4$ or $4 / 4$ time.

\section{Bow}

2/4 time.

Second year of training. first half, 4-4,5-year-old. (lesson duration is 60 minutes, with additional 15 minutes of performance practice)

\section{WARM UP}


This set is a part of the second half of the first year of training, the feet position changes and the shoulder warm up is more complicated.

Bow

2/4 time.

\section{Walking around}

New elements are added to the set of Basic module exercises:

1) walking pointing feet (march);

2) walking on tip toes (march);

3) walking on the heels (march);

4) walking on tip toes in deep squat from VI position («geese»), straight back, hands on knees;

5) running on tiptoes;

6) steps with pointed feet, hands in the starting position (march);

2/4 time.

\section{Shoulders warm up}

4/4 time.

\section{Wrists warm up}

The exercise is aimed at developing coordination and fine motor skills.

1) «Wrists turnouts»

2) «Fingers meet»

3) «Little beaks»

$4 / 4$ time.

\section{PARTERRE GYMNASTICS}

During the second year of training, parterre gymnastics becomes more complicated as the basic module of the first year is mastered, new exercises are added.

The set of exercises sitting on the floor is complicated by feet turnout in I position and additional exercises.

\section{Feet work}

The new turnout exercises and the exercise of "little book" are added. This set of exercises is aimed at stretching and strengthening the ankle and popliteal ligaments, as well as the development of lower turnout.

2/4.

\section{Folds}

The exercise is aimed at stretching the popliteal ligaments, stretching and strengthening the back muscles 2/4 time.

\section{Fishing rod}

The exercise is aimed at hip joints stretching, stretching and strengthening of the back. $3 / 4$ time.

\section{Sitting frog}

The exercise is aimed at developing hip joints turnout and inguinal ligaments stretching. $3 / 4$ time.

A new exercise is added:

\section{Preparation for Battements tendus}

The exercise is aimed at the development (strengthening) of legs muscles and ligaments, joints turnout, strengthening of abdominal muscles and coordination. 
$4 / 4$ time.

\section{Sunbeam (preparation for Relevé lent)}

The exercise is complicated: it is performed as preparation for the Relevé lent in the I position. 2/4 time.

A new exercise is added:

\section{Preparation for Grands battements jeté}

The exercise is aimed at strengthening and stretching the popliteal and inguinal ligaments. 3/4 time.

Next, the complexity and sequence of exercises of the Basic module changes, new exercises are added. Instead of "Mouse in the hole" exercise, the following set of exercises is performed:

\section{Exercises to develop back flexibility}

A set of exercises is aimed at stretching and strengthening the back and hip muscles. Shoulder joints are also actively involved.

2/4 time.

Then, the exercises of the second half of the first year are performed:

\section{Plane}

The exercise is aimed at strengthening the muscles of the back. The exercise is performed in pairs by two children with different tasks.

2/4 time.

\section{Roly-poly doll}

The exercise is aimed at strengthening the muscles of the abdomen and neck. The exercise is performed in pairs.

2/4 time.

\section{Cat}

The exercise "Cat» is combined with the exercise "Hammock». They are performed in succession to one piece of music repeated 2-4 times for each part.

The exercise is aimed at developing back flexibility, strengthening abdominal muscles, stretching the heel strings (Achilles) and the hamstrings, as well as at working the thoracic spine muscles. 2/4 time.

New exercises are added:

\section{Flexible cat}

The exercise is aimed at strengthening the back and abdominal muscles. 2/4 time.

\section{Cat lifts the paws}

The exercise is aimed at strengthening the muscles of the back and hips, coordination of the body. 2/4 time.

Then, the exercises of Basic module are performed.

\section{Fox}

The exercise is aimed at strengthening the muscles of back, abdomen, hips and the popliteal ligaments. 2/4 time.

Train

The exercise is aimed at working the hip joints, back and abdomen muscles, coordination of movements. 2/4 time.

\section{Suffering}

The exercise is aimed at stretching the popliteal ligaments, heel strings (Achilles) and back muscles. 4/4 time.

\section{Gate}

The exercise is complicated by some movements of "stairs».

The exercise is aimed at stretching the popliteal ligaments, heel strings (Achilles), inguinal ligaments, hip joints work. 2/4 time. 


\section{Bicycle}

The exercise is aimed at strengthening the abdominal muscles. 2/4 time.

\section{Teddy Bear}

The exercise is aimed at stretching and relaxation of the back muscles at the spinal column. 2/4 time.

\section{Exercises with accessories}

These exercises are aimed at platy podia prevention, massage and the development of coordination when working with an accessory. They are performed with massage mat, inflatable needle balls ( $7 \mathrm{~cm}$ of diameter) and hemispheres.

\section{Exercises with a ball for hands}

4/4 time.

\section{Exercises with a ball for legs}

A set of exercises is performed without stopping.

$2 / 4$ time.

\section{Magic lock}

The exercise is aimed at developing coordination, strengthening the abdominal muscles, popliteal ligaments and feet work.

$4 / 4$ time.

\section{A new exercise is added}

\section{Balance}

The exercise is aimed at strengthening of back and abdominal muscles, as well as at developing attention and coordination. 4/4 time.

\section{Massage mat}

The exercise is aimed at preventing platy podia and strengthening the foot arch.

Steps on the massage mat and hemispheres (barefoot) with musical accompaniment. 3/4 time.

\section{MILIEU}

\section{Musicians}

A set of coordination exercises, developing imaginative thinking, musicality and concentration. Play-based activities.

1) «Piano»

2) «Flute»

3) «Drums»

2/4 and $3 / 4$ time.

\section{Jump}

Jumps from free I position.

2/4 time.

\section{Acting talent}

The exercises are aimed at the development of dance imagination, coordination and musicality. Interaction between trainee and teacher, trainee and partner.

1) «Rain»

2) «Snowflake»

3) «Snowballing»

2/4 time.

\section{Preparation for Port de bras}

1) «Bras bas»

2) «l position of arms» 4/4 time. 


\section{Diagonal}

Exercises are performed on a diagonal (one after another).

1) Marching (legs lift knees up)

2) Hops

3) «Horses»

4) Run lifting heels to hips

5) «Swans» (walking high on tiptoes). 2/4 and 3/4 time.

\section{Exercise for coordination}

4/4 time.

\section{Musical interlude}

Arms movements and galloping are added to the Basic module exercises.

The exercises are aimed at developing musical ear and coordination. Starting position: children form a circle; their feet are in free first position.

1) Clapping hands at strong beats

2) «Gymnastics»

3) Galloping around

2/4 time.

Jumping rope

Exercises are aimed at coordination and developing turnout. Exercises are performed on a jumping rope stretched on the floor.

1) «Rope-walker»

2) «Sidestep»

3) «Jumping rope»

2/4 time.

\section{CHOREOGRAPHIC MINIATURES}

The exercises of this set are aimed at the development of dance imagination, improvisation, musicality and rhythmic hearing.

The Basic module of exercises is performed.

\section{Rain}

1) «Raining» hands

2) «Raining» feet.

$3 / 4$ time.

A new dancing exercise is added to the Basic module

\section{Dance with a doll}

2/4 time.

\section{Dance improvisation}

This exercise is aimed at the development of dance imagination and achieving the children's creative potential.

The theme of the dance sketch can be chosen by the child him-/herself or with the help of the teacher. The use of fans, kerchiefs, tambourines is possible.

2/4 time

\section{Performing practice}

Performing dance numbers and (or) practicing their individual elements. 


\section{STRETCHING}

The exercises are aimed at the passive stretching of inguinal and popliteal ligaments and muscles (cross split). Stretching under the weight of legs is not traumatic, since the exercise is performed slowly and without additional pressure of body or external force on the ligaments and muscles.

\section{Stretching lying on the stomach»}

6/8 time.

\section{Stretching lying on the back}

6/8 time.

Bow

2/4 time.

Second year of training. Second half year, 4-4,5-year-old. (Lesson duration is 60 minutes, 15 minutes of performance practice added)

\section{WARM UP}

This set is a part of the second half of the first year of training, the feet position changes and the shoulder warm up is more complicated.

\section{Bow}

2/4 time.

\section{Walking around}

1) walking pointing feet (march);

2) walking on tip toes (march);

3) walking on the heels (march);

4) walking on tip toes in deep squat from VI position («geese»), straight back, hands on knees;

5) running on tiptoes;

$6)$ steps with pointed feet, hands in the starting position (march);

4/4 time.

\section{Shoulders and wrists warm up}

The set of exercises includes the combination of previous and new exercises. 2/4.

\section{PARTERRE GYMNASTICS}

\section{Feet work}

The set of exercises sitting is aimed at stretching and strengthening ankle and popliteal ligaments and developing lower turnout.

2/4 time.

\section{Folds}

The exercise is complicated by turnout position and arms work. It is aimed at stretching the popliteal ligaments, stretching and strengthening the back muscles.

\section{2/4 time.}

\section{Sitting frog}

The exercise is complicated by new movements aimed at developing turnout.

The exercise is aimed at developing turnout of the hip joints and stretching of the inguinal ligaments. $3 / 4$ time.

\section{Fishing rod}

The exercise is aimed at developing flexibility of hip joints, stretching and strengthening of the back. $3 / 4$ time. 
A new exercise is added:

Preparation for Battements tendus

The exercise is aimed at the development (strengthening) of the muscles and ligaments of the legs, turnout, as well as coordination.

$4 / 4$ time

A new exercise is added:

Preparation for Passé

The exercise is aimed at working hip joints, inguinal ligaments and hamstring, as well as at turnout development.

4/4 time.

Sunbeam (preparation for Relevé lent)

The exercise is aimed at working hamstring and popliteal ligament.

4/4 time.

A new exercise is added:

Preparation for Grands battements jeté

The exercise is aimed at stretching and strengthening of popliteal and inguinal ligaments.

3/4 time.

\section{9 «Exercises for back flexibility»}

The exercise is aimed at stretching and strengthening of back and hips muscles. The shoulder joints are also active.

2/4 time.

A new exercise is added:

\section{Swimming}

The exercise is aimed at stretching and strengthening of back and hips muscles.

2/4 time.

\section{Plane}

Arms position is more complicated.

The exercise is aimed at strengthening of back muscles. It is performed in pairs by children with different tasks.

2/4 time.

\section{Roly-poly doll}

The exercise is aimed at strengthening of neck and abdomen muscles. It is performed in pairs.

2/4 time.

\section{Flexible cat}

The exercise is aimed at strengthening of back and abdomen muscles.

2/4 time.

\section{Cat lifts the paws}

The exercise is aimed at the development of coordination, strengthening of back muscles, body control and balance.

2/4 time.

\section{Fox}

The exercise is aimed at strengthening the muscles of back, abdomen, hips and the popliteal ligaments. 2/4 time.

\section{Cat}

The exercise is aimed at developing back flexibility, strengthening abdominal muscles, stretching the heel strings (Achilles) and the hamstrings, as well as at working the thoracic spine muscles. 
2/4 time.

\section{Train}

The exercise is aimed at working hip joints, back and abdomen muscles and movement coordination.

2/4 or 4/4 time.

\section{Suffering}

The exercise is aimed at stretching the popliteal ligaments, heel strings (Achilles) and back muscles.

4/4 time.

\section{Gate}

The exercise is aimed at stretching the popliteal ligaments, heel strings (Achilles), inguinal ligaments, hip joints work.

2/4 time.

\section{Bicycle}

The exercise is complicated by new elements performed in succession.

The exercise is aimed at strengthening of abdominal muscles.

2/4 time.

\section{Teddy bear}

The exercise is aimed at stretching and relaxing of back muscles along the spine.

2/4 time.

\section{Exercises with accessories}

These exercises are aimed at platy podia prevention, massage and development of coordination when working with an accessory. They are performed with massage mat, inflatable needle balls ( $7 \mathrm{~cm}$ of diameter) and hemispheres.

\section{Exercises with a ball for hands}

$4 / 4$ time.

\section{Exercises with a ball for legs}

2/4 time.

\section{Magic lock}

The exercise is aimed at developing coordination, strengthening the abdominal muscles, popliteal ligaments and feet work.

$4 / 4$ time

\section{Balance}

The exercise is aimed at strengthening of back and abdominal muscles, as well as at developing attention and coordination. It is performed in stages to work well different elements. 4/4 time.

\section{Massage mat}

The exercise is aimed at preventing platy podia and strengthening the foot arch.

Steps on the massage mat and hemispheres (barefoot) with musical accompaniment.

$3 / 4$ time.

\section{MILIEU}

\section{Musicians}

A set of coordination exercises, developing imaginative thinking, musicality and concentration. Play-based activities. It is advisable to introduce other instruments.

1) «Piano»

2) «Flute»

3) «Drums»

2/4 and 3/4 time. 


\section{Jump}

2/4 time.

Instead of «Acting talent» set, the «Preparation for Port de bras» is performed

Preparation for Port de bras»

The second and third arms position is added.

1) «Bras bas»

2) «First position of arms»

4/4 time.

\section{Diagonal}

Exercises are performed on a diagonal (one after another).

1) Marching (lift legs knee up)

2) Hops

3) «Horses»

4) Run lifting heels to hips

5) Pas chasse forward

6) «Butterflies» (walking high on tiptoes).

2/4 and 3/4 time.

\section{Exercise for coordination}

2/4 time.

\section{Polka}

2/4 time.

\section{Gallop with jumping}

2/4 time.

\section{Musical interlude}

Arms movements and galloping are added to the Basic module exercises.

The exercises are aimed at developing musical ear and coordination.

1) Clapping hands at strong beats

2) «Gymnastics»

3) Galloping around

\section{2/4 time.}

\section{Jumping rope}

These exercises are aimed at coordination and developing turnout. Exercises are performed on a jumping rope stretched on the floor.

1) «Rope-walker»

2) «Sidestep»

3) «Jumping rope»

2/4 time.

\section{CHOREOGRAPHIC MINIATURES}

The exercises of this set are aimed at the development of dance imagination, improvisation, musicality and rhythmic hearing.

\section{Rain}

This set of exercises is performed to one piece of music

1) «Raining» hands

2) «Raining» feet.

3/4 time. 


\section{The Red Riding-hood and the Wolf}

The Polka steps, gallop, run on tiptoes and art of acting are used to create the image of Red Riding hood. The role of Wolf is played by the teacher.

2/4 time.

\section{Dance improvisation}

This exercise is aimed at the development of dance imagination and achieving the children's creative potential.

The theme of the dance sketch can be chosen by the child him-/herself or with the help of the teacher. The use of fans, kerchiefs, tambourines is possible.

2/4 time

\section{Performing practice}

Performing dance numbers and (or) practicing their individual elements.

\section{STRETCHING}

The exercises are aimed at the passive stretching of inguinal and popliteal ligaments and muscles (cross split). Stretching under the weight of legs is not traumatic, since the exercise is performed slowly and without additional pressure of body or external force on the ligaments and muscles.

\section{Stretching lying on the stomach}

6/8 time.

\section{Stretching lying on the back}

\section{6/8 time}

Roll-up

2/4 time.

Bow

2/4 time.

\section{Third year of training 5-6-year-old. (Lesson duration is 90 minutes)}

\section{WARM UP}

Bow

2/4 time.

\section{Walking around}

2/4 time.

\section{Shoulders and wrists warm up}

The set of exercises includes some new movements.

2/4 time.

\section{PARTERRE GYMNASTICS}

During the second year of training, parterre gymnastics becomes more complicated as the basic module of the first and second year is mastered, new exercises are added.

\section{Feet work}

The set of exercises sitting is aimed at stretching and strengthening of ankle and popliteal ligaments and at developing lower turnout.

All the set is performed without pauses, in succession $(2.1 ; 2.2 ; 2.3 ; 2.4)$.

2/4 time.

\section{Sitting frog}

The exercise is complicated by new movements aimed at developing turnout. 
The exercise is aimed at developing turnout of the hip joints and stretching of the inguinal ligaments.

$3 / 4$ time.

\section{Folds}

The exercise is aimed at stretching the popliteal ligaments, stretching and strengthening the back muscles. 2/4 time.

\section{Fishing rod}

The exercise is aimed at working hip joints, stretching and strengthening of the back

3/4 time.

\section{Preparation for Battements tendus}

2/4 time.

Preparation for Battements tendus jeté

2/4 time.

\section{Clock hand}

The exercise is aimed at working internal muscles of thigh, strengthening of leg muscles and ligaments.

2/4 time.

Sunbeam (preparation for Relevé lent)

The exercises 2.8 and 2.9 are performed as one set.

The exercise is aimed at working out popliteal ligament and inner thigh

4/4 time.

\section{Preparation for Passé}

The exercise is aimed at working out hip joints, inguinal ligaments and hamstring.

4/4 time.

\section{Preparation for Developpé}

4/4 time.

\section{Preparation for Grands battements jeté}

The exercise is aimed at stretching and strengthening of popliteal and inguinal ligaments.

2/4 time.

\section{Exercises for back flexibility}

The exercise is aimed at stretching and strengthening of back and hips muscles. The shoulder joints are also active.

2/4 time.

\section{Swimming}

The exercise is aimed at stretching and strengthening of back and hips muscles.

2/4 time.

\section{Boat}

The exercise is aimed at strengthening of back muscles. It is worked out since the second half year.

2/4 time.

\section{Flexible cat}

The exercise is aimed at strengthening of back and abdomen muscles.

2/4 time.

\section{Cat lifts the paws}

The exercise is aimed at the development of coordination, strengthening of back muscles, body control and balance.

2/4 time.

\section{Cask}

The exercise is aimed at strengthening abdominal muscles.

$3 / 4$ time. 


\section{Ballerina}

The exercise is aimed at stretching the inguinal and popliteal ligaments, as well as at strengthening back muscles and the development of coordination.

$4 / 4$ time.

\section{Gate}

The exercise is aimed at stretching of popliteal and inguinal ligaments, heel string and at the development of hip joints mobility.

2/4 time.

\section{Abs lying}

The exercise is aimed at strengthening abdominals, thigh and back muscles. It is complicated by new elements.

\section{2/4 time.}

\section{Balance}

The exercise is aimed at strengthening abdominals and back muscles, development of attention and coordination.

$4 / 4$ time.

\section{Teddy bear}

The exercise is aimed at stretching and relaxing of back muscles along the spine.

$2 / 4$ time.

\section{MILIEU}

\section{Points in the hall}

The exercise is aimed at exploring the hall using points.

2/4 time.

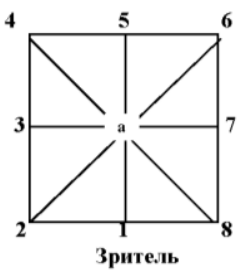

\section{First Port de bras}

It is performed since the first half year.

4/4 time.

\section{Temps sauté}

\section{2/4 time.}

\section{Changement de pieds}

\section{2/4 time.}

\section{Diagonal}

Exercises are performed on a diagonal (one after another).

1) Marching steps with jumps

2) Marching steps are replaced by hops

3) «Polka steps» with hops

4) Alternating Polka and gallop

5) Leaps forward

6) Pas chasse forward

7) Pas de bourreé suivi sideward on tiptoes.

2/4, 3/4 and 4/4 time. 


\section{EXERCICE A LA BARRE}

The height adjustment of ballet barre is indispensable.

At the initial stage, the children learn the arms and body position at the ballet barre.

Pas relevé

It is performed in first and fifth positions.

$3 / 4$ time.

\section{Demi-plié}

4/4 time.

\section{Battements tendus}

2/4 time.

Preparation for Battements tendus jeté

2/4 time.

Sur le cou-de-pied

2/4 time.

Pas de bourrée

2/4 time.

\section{Stretching exercise}

2/4 time.

\section{CHOREOGRAPHIC MINIATURES}

The exercises of this set are aimed at the development of dance imagination, improvisation, musicality and rhythmic hearing.

\section{Polka improvisation}

2/4 time.

\section{Dance miniature with an accessory}

Accessory: tambourine. Interaction in pair, trio and quartet.

4/4 time.

\section{Dance improvisation}

This exercise is aimed at the development of dance imagination and achieving the children's creative potential.

The theme of the dance sketch can be chosen by the child him-/herself or with the help of the teacher. The use of fans, kerchiefs, tambourines is possible.

2/4 time

\section{Performing practice}

Performing dance numbers and (or) practicing their individual elements.

Includes additional movements Pas Balance, Temps lié, Pas couru, Pas de grâce, waltz steps forward and backward.

\section{STRETCHING}

The exercises are aimed at the passive stretching of inguinal and popliteal ligaments and muscles (cross split). Stretching under the weight of legs is not traumatic, since the exercise is performed slowly and without additional pressure of body or external force on the ligaments and muscles.

\section{Stretching lying on the stomach}

$6 / 8$ time.

\section{Stretching lying on the back}

$6 / 8$ time 


\section{Roll-up}

2/4 time.

Split

Front splits are made from each leg. The duration depends on the level of training and stretching of children. Bow

$2 / 4$ time.

\section{CONCLUSIONS}

The methodological basis of the initial choreographic training at an early age is the parterre exercise, aimed at the development and strengthening of the musculoskeletal system, and play-based techniques with a focus on revealing a creative personality. By the age of five, the child is capable of synchronized exercise and mirror perception. During this period, the basis of training includes complicated elements of parterre gymnastics and the initial ballet exercise. A correct and appropriate musical accompaniment should not be changed. Each piece of music must correspond to a certain movement, since at this age the child remembers well aurally. Well-formed associations with musical accompaniment in the performance of understandable elements and combinations, make it much easier for a child to fulfil the teacher's demands, not to think about the order, and to focus on the correct performance of the exercise. In this regard, it is not recommended to change the order of exercises during the first year of training. When performing any exercise, special attention should be paid to the starting position and its completion. It is important to teach to put a "point" at the end of the exercise, thus raising attention to the integrity of the exercise from beginning to end. So, during the first year of three-year-olds education the children cognize their bodies, getting used to physical activity, alternating with play-based and imaginative exercises which support the child's attention and interest in the lesson. In this period, the process of memorizing exercises is carried out to further work out the quality of their performance. By the end of the first half-year, a trainee should achieve the following results:

- To know the body parts (knees, shoulders, feet, back, fingers, toes etc.;

- To execute movements in correct first- and sixth-feet positions hands on waist;

- To move correctly in the ballet hall (to get into lane facing the teacher; to form a circle);

- To remember names of exercises and their order;

- To listen to the teacher and to hear him well, to perform simple exercises without teacher.

In the second half of the first year of study, special attention is paid to the relationship of exercises and musical accompaniment. The third feet position is introduced.

By the end of the second half year, the child should achieve the following results:

- To know the right and left side of the body (arm, leg, shoulder);

- Understand the position of pointed feet and knees;

- To be able to perceive musical tempo and to understand the nature of music;

- To perform movements forming different figures.

The methodology of the second year of study is aimed at the quality of performing exercises, the coordination of head and body work, the sensitivity to teacher's remarks and fulfilment of various tasks.

From the age of four, it is necessary to proceed to performing movements using turnout. It is advisable to introduce classical dance elements, studying the main positions of arms and legs, muscle stretching and strengthening, as well as stage practice. 
By the end of the first half of the second year of education, the child should achieve the following results:

- To perform exercises without teacher's demonstration;

- To execute movements from legs turnout;

- To perform accurately and correctly all the exercises of the first year.

In the second half of the year it is possible to shift the emphasis on improving the technique of performing movements, since the children already withstand the stresses of the lesson, is able to perceive the teacher's remarks and consciously correct the mistakes.

By the end of the second half of the second year of education, the child should achieve the following results:

- To move freely in the ballet hall at the demand of the teacher;

- To know the first, third- and fifth-feet positions;

- To know the position of arms when performing the preparatory, first, second and third positions;

- To perform well strength exercises;

- To perform well stretching exercises.

During the third year of training (from the age of 5), play-based elements are excluded, and more technically complex movements and combinations are added to the lesson program. The correct positions of arms (preparatory, first, second, third) and legs (first, second, third, fifth) are reinforced. The first and second port de bras are studied. The children start to study basic ballet exercise a la barre and au milieu.

By the end of the year, the technique of performing exercises on flexibility, stretching and muscle strength is improved. It is important that the child is able to explain how to perform the movement correctly and to concentrate before starting the movement.

By the end of the third year, the child should achieve the following results:

- To perform all the exercises understanding the tasks;

- To perform exercises and combinations in succession one after another;

- To hear strong beats and calculate the rhythm of music;

- To perceive and perform previously learned movements in different combinations;

- To do side and frontal splits;

- To know different locations in the hall and correctly move through it performing choreographic combinations in movement;

- To form lines, circle, diagonal with other children;

- To be able to express themselves in movement and music;

- To keep the lesson time with a full load;

- To perform all the coordinated movements quickly.

The most important in the process of teaching children of this age is their immersion in the atmosphere of choreographic art, classical music, discipline and independent creative activity. One of the main factors influencing the result is the teacher himself and his willingness to interest and involve children in the process of work and creativity. 


\section{REFERENCES}

Gestwicki, C. (2013). Developmentally appropriate practice: Curriculum and development in early education. Cengage Learning.

Groark, C. J., Muhamedrahimov, R. J., Palmov, O. I., Nikiforova, N. V., \& McCall, R. B. (2005). Improvements in early care in Russian orphanages and their relationship to observed behaviors. Infant Mental Health Journal: Official Publication of The World Association for Infant Mental Health, 26(2), 96-109. https://doi.org/10.1002/imhj.20041

Hendrick, J., \& Weissman, P. (1996). The whole child: Developmental education for the early years. Merrill.

McLachlan, C., Fleer, M., \& Edwards, S. (2018). Early childhood curriculum: Planning, assessment and implementation. Cambridge University Press. https://doi.org/10.1017/cbo9781107282193.006

Pfeiffer, K. A., Saunders, R. P., Brown, W. H., Dowda, M., Addy, C. L., \& Pate, R. R. (2013). Study of Health and Activity in Preschool Environments (SHAPES): Study protocol for a randomized trial evaluating a multi-component physical activity intervention in preschool children. BMC Public Health, 13(1), 728. https://doi.org/10.1186/1471-2458-13-728

Powell, D., Dunlap, G., \& Fox, L. (2006). Prevention and intervention for the challenging behaviors of toddlers and preschoolers. Infants \& Young Children, 19(1), 25-35. https://doi.org/10.1097/00001163-200601000-00004

Rolfe, S. A. (2004). Rethinking Attachment for Early Childhood PracticePromoting Security, Autonomy and Resilience in Young Children. Allen \& Unwin.

Vanderloo, L. M. (2014). Screen-viewing among preschoolers in childcare: a systematic review. BMC pediatrics, 14(1), 205. https://doi.org/10.1186/1471-2431-14-205 